\title{
Revisión del efecto de la vitamina E sobre biomarcadores inflamatorios asociados a la obesidad
}

\section{Review of the effect of vitamin E on obesity-associated inflammatory biomarkers}

\author{
Paola Ventura-Pérez, ${ }^{a}$, Mario Mateos-Islas ${ }^{b}$, José A. Ariza-Ortega $^{c}$
}

\begin{abstract}
:
Introduction: Vitamin $\mathrm{E}$ is an essential nutrient and in nature it exists in various isoforms, and due to its isoform, $\alpha$-tocopherol (15 mg / day) has a higher antioxidant activity, avoiding lipid peroxidation, as well as an anti-inflammatory effect by decreasing and / or inhibiting the release of pro-inflammatory substances (CRP, TNF- $\alpha$ and IL-6) secreted by adipose tissue in obesity. Objective: To collect information about the effect of vitamin E on the inflammatory biomarkers associated with obesity. Material and methods: A bibliographic review was carried out through electronic databases. Results: Based on 16 articles, it was found that the intake of vitamin $\mathrm{E}$ at concentrations of $372.50 \mathrm{IU} / \mathrm{d}$ to $1500 \mathrm{IU} / \mathrm{d}$ significantly decreased the levels of C-reactive protein (CRP), TNF- $\alpha$ and IL-6. Conclusion: Vitamin $\mathrm{E}$ at a concentration of $400 \mathrm{IU} / \mathrm{d}$ exerts an inhibitory effect on the levels of inflammatory biomarkers associated with obesity.
\end{abstract}

Keywords:

Inflammation, tocopherol, vitamin E

\section{Resumen:}

Introducción: La vitamina $\mathrm{E}$ es un nutriente esencial y en la naturaleza existe en diversas isoformas, y debido a su isoforma, el $\alpha$ tocoferol (15 mg/día) presenta una mayor actividad antioxidante, evitando la peroxidación lipídica, así como un efecto antiinflamatorio al disminuir y/o inhibir la liberación de sustancias proinflamatorias (PCR, TNF- $\alpha$ e IL-6) secretadas por el tejido adiposo en la obesidad. Objetivo: Recopilar información acerca del efecto de la vitamina E sobre los biomarcadores inflamatorios asociados a la obesidad. Material y métodos: Se realizó una revisión bibliográfica a través de bases de datos electrónicas. Resultados: Con base en 16 artículos, se encontró que la ingesta de vitamina E a concentraciones de 372.50 UI/día a 1500 UI/día disminuyen significativamente los niveles de proteína C reactiva (PCR), TNF- $\alpha$ e IL-6. Conclusión: La vitamina E a una concentración de 400 UI/día ejerce un efecto inhibidor en los niveles de biomarcadores inflamatorios asociados a la obesidad.

\section{Palabras Clave:}

Inflamación, tocoferol, vitamina $E$

\section{Introducción}

La Organización Mundial de la Salud (OMS), define a la obesidad como una acumulación anormal o excesiva de grasa (principalmente tejido adiposo blanco) que puede perjudicar la salud ${ }^{1}$. A partir de la Encuesta Nacional de Salud y Nutrición ENSANUT en el 2018 se sabe que la prevalencia nacional de obesidad abdominal fue de $88.4 \%$ en mujeres adultas, 15.7 puntos porcentuales mayor que en hombres $72.7 \%$, lo que se refleja como uno de los problemas más prevalentes en la población. ${ }^{2}$

Ha sido caracterizada como un proceso inflamatorio crónico sistémico de bajo grado, a través del cual, existe 
un aumento de mediadores inflamatorios principalmente Proteína C Reactiva (PCR), Factor de Necrosis Tumoral alfa $($ TNF- $\alpha)$ e Interleucina-6 (IL-6), secretados particularmente por el tejido adiposo visceral $^{3}$ acompañado de una serie de mecanismos que vinculan el desarrollo de la obesidad con la inflamación como se observa en la figura 1.

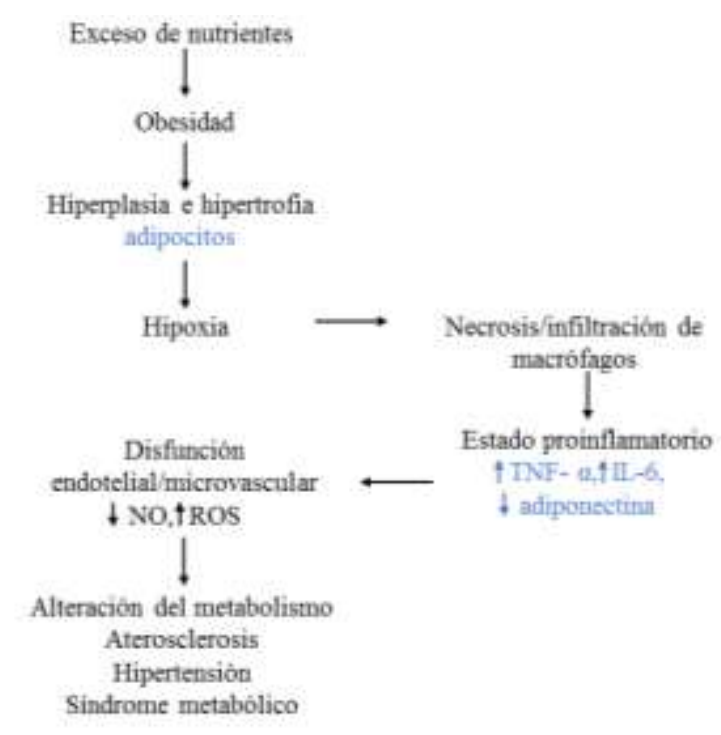

Figura 1. Vínculo del desarrollo de la obesidad con procesos inflamatorios. Adaptado de ${ }^{4}$<smiles>Cc1c(C)c2c(c(C)c1O)CC[C@](C)(CCC[C@H](C)CCC[C@H](C)CCCC(C)C)O2</smiles>

$\gamma$-Tocoferol<smiles>Cc1c(O)cc2c(c1C)O[C@](C)(CCC[C@H](C)CCC[C@H](C)CCCC(C)C)CC2</smiles><smiles>CC(C)=CCC/C(C)=C/CC/C(C)=C/CC[C@]1(C)CCc2c(C)c(O)c(C)c(C)c2O1</smiles>

$\gamma$-Tocotrienol<smiles>CC(C)=CCC/C(C)=C/CC/C(C)=C/CC[C@]1(C)CCc2cc(O)c(C)c(C)c2O1</smiles>

El interés que genera determinar el efecto de la vitamina $E$ en este padecimiento, se debe a que se ha reportado que la vitamina $E$ ejerce un efecto antiinflamatorio, al disminuir la PCR e inhibir la liberación de citocinas proinflamatorias anteriormente mencionadas. ${ }^{4}$ Por lo tanto, el objetivo del presente trabajo fue recopilar información acerca del efecto de la vitamina E sobre los biomarcadores inflamatorios asociados a la obesidad.

\section{Generalidades de la Vitamina E}

En la naturaleza existen diversas isoformas de vitamina E como son la $\alpha, \beta, y$ y $\delta$ de tocoferol y la $\alpha, \beta, \gamma$ y $\delta$ de tocotrienol (Figura 2). ${ }^{5}$ La vitamina $E$, fue descubierta en las verduras de hoja verde (62 mg/100g), y aislada en el aceite de germen de trigo (200 mg/100g), en estos alimentos la principal isoforma es la $\alpha$-tocoferol, mientras que en frutas (litchi y uvas) y semillas (maíz, cebada y trigo), predomina la isoforma de $y$-tocoferol., ${ }^{6,7} \mathrm{El} \alpha$ tocoferol se ha demostrado que es la forma biológicamente más activa y predomina en la dieta, tejidos y plasma $^{8}$ comparado con las isoformas $\beta$ tocoferol y el $\gamma$-tocoferol, que muestran una actividad vitamínica reducida (15 al 20\%) mientras que el $\delta$ tocoferol es casi inactivo. ${ }^{9}$

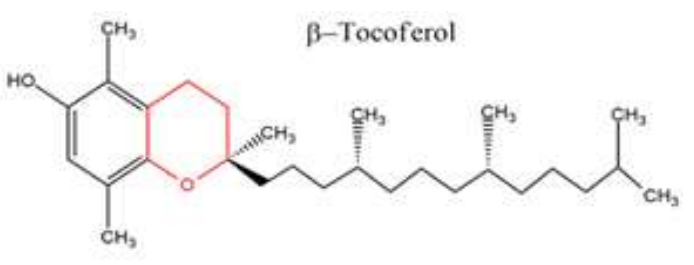

8-Tocoferol<smiles>Cc1cc(O)cc2c1O[C@](C)(CCC[C@H](C)CCC[C@H](C)CCCC(C)C)CC2</smiles><smiles>CC(C)=CCC/C(C)=C/CC/C(C)=C/CC[C@]1(C)CCc2c(C)c(O)cc(C)c2O1</smiles>

8-Tocotrienol

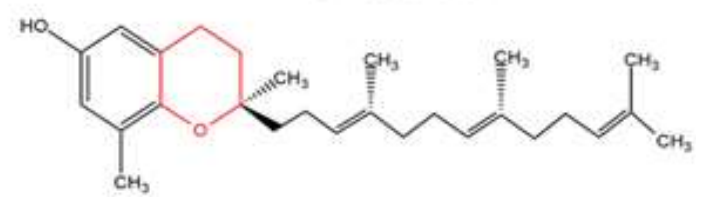

Figura 2. Estructura química de los tocoferoles y tocotrienoles. (Perkin Elmer Informatics, Inc. 1998 - 2017). 
Por el contrario, los tocotrienoles se caracterizan por presentar en su conformación un anillo de cromanol unido a los tocoferoles (marcado de color rojo), mientras que la cadena lateral de filo hidrófobo de 16 carbonos está completamente saturada en tocoferoles y en los tocotrienoles tiene 3 dobles enlaces trans (Figura 2). ${ }^{5}$ Debido a su estructura química formada por isoprenoides que conforman los tocoferoles, la vitamina $\mathrm{E}$ es una sustancia insoluble en agua y soluble en lípidos y disolventes orgánicos, por lo que se encuentra dentro de la clasificación de vitaminas liposolubles, se absorbe en el intestino delgado similar a las grasas y se almacena en el cuerpo (principalmente en el tejido adiposo) durante periodos de tiempo variables. ${ }^{10,11}$

La vitamina $E$ es un nutriente esencial, que tiene que ser aportado necesariamente por la dieta debido a que no puede formarse en el organismo. ${ }^{12}$ A continuación, en la Tabla 1 se muestran algunos alimentos que contienen tocoferoles y tocotrienoles, que representan a la familia de la vitamina $\mathrm{E}$.

Tabla 1.- Vitamina E de algunas fuentes alimentarias

\begin{tabular}{|c|c|c|c|}
\hline \multirow{2}{*}{ Alimentos } & \multicolumn{3}{|c|}{ Concentración (mg/100g) } \\
\hline & Vitamina E & $\alpha$-tocoferol & $\alpha$ y $\gamma$-tocotrienoles \\
\hline Aceite de girasol & ${ }^{14} 55$ & ${ }^{16} 50-60$ & ${ }^{16} 0.11$ \\
\hline Aceite de maíz & ${ }^{14} 31$ & - & ${ }^{16} 1.94-2.00$ \\
\hline Almendras & ${ }^{14} 25$ & ${ }^{13} 5.02$ & - \\
\hline Aceite de oliva & ${ }^{14} 12$ & ${ }^{16} 11.9-17$ & - \\
\hline Trigo & ${ }^{17} 1.64$ & ${ }^{17} 0.95$ & 171.09 \\
\hline Quínoa & ${ }^{17} 5.35$ & ${ }^{17} 4.74$ & - \\
\hline Aceite de palma & - & & $1560-100$ \\
\hline
\end{tabular}

\section{Absorción y metabolismo de la vitamina $E$}

El efecto de la vitamina $E$, tocoferoles y tocotrienoles depende de su absorción y metabolismo. En la Figura 3 se muestra el proceso metabólico de la vitamina $E$ hasta su distribución en los tejidos.

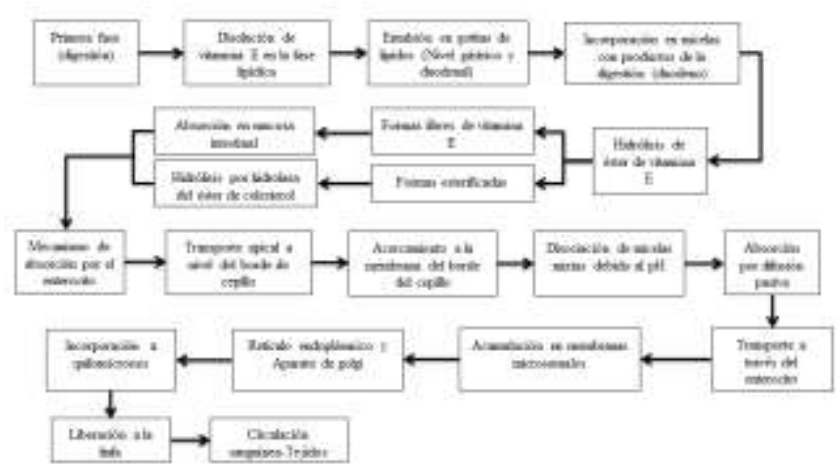

Figura 3. Metabolismo de la vitamina E. Adaptado de ${ }^{9}$

Se ha reportado que durante la ingesta diaria de vitamina $E$, se absorbe entre un $20-80 \%$, y estos porcentajes varían en base a la ingesta de lípidos en la dieta. ${ }^{18} \mathrm{Sin}$ embargo, estos porcentajes son suficientes para ejercer el efecto antiinflamatorio y antioxidante, ya que se ha reportado que después de su absorción, en el plasma sanguíneo hay una concentración que se encuentra entre $<20$ a $>50 \mu \mathrm{mol} / \mathrm{L}$, concentración que se encuentra dentro del requerimiento promedio estimado en la población adulta con $30 \mu \mathrm{mol} / \mathrm{L}^{19,20}$

\section{Procesos inflamatorios asociados a la obesidad}

La inflamación, es una secuencia de eventos que comprende dos fases, la primer fase que es de inducción, donde se activa una respuesta inmune rápida, como una defensa eficaz en el huésped, y la segunda fase que es de resolución, donde se reduce la inflamación, y se equilibra la homeostasis en el tejido (una vez que se ha eliminado la señal de peligro). ${ }^{21}$ En la Figura 4 se muestra el proceso inflamatorio y las células que participan en su resolución. 


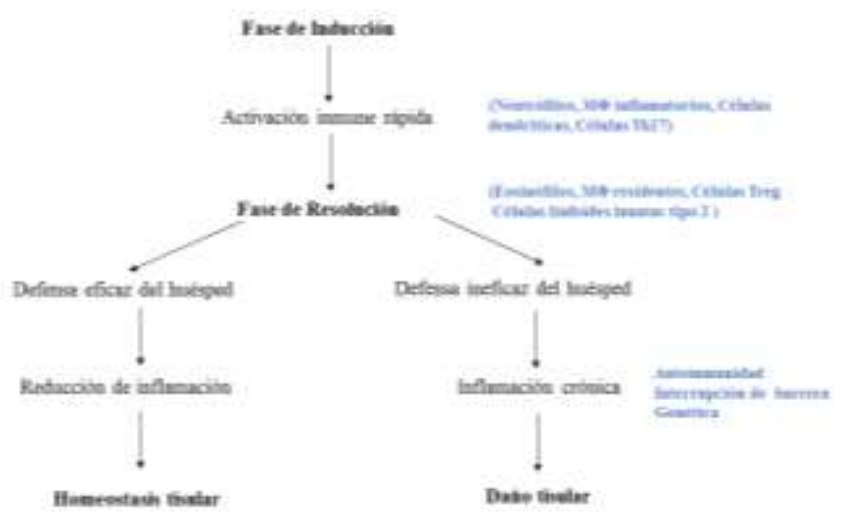

Figura 4. Respuesta inmunológica en el proceso inflamatorio. Adaptado de 21

Durante la primera fase de la inflamación, se generan dos tipos, aguda (caracterizada por edema y migración de leucocitos) y crónica (con presencia de linfocitos y macrófagos y proliferación de vasos sanguíneos y tejido conectivo). ${ }^{3}$ El papel central de la inflamación se le atribuye al hígado, debido a que al drenar los ácidos grasos libres y el triacilglicerol circulante, desencadena a la vez la expresión de los hepatocitos y la liberación de PCR. ${ }^{3}$

En el tejido adiposo de la población con obesidad, se pueden encontrar un mayor número de macrófagos, específicamente de los macrófagos proinflamatorios de tipo M1. ${ }^{22}$ Éstos son estimulados generalmente por el tipo de citocinas T-helper 1 (Th1), como el interferón-y (IFNY) o por patrones moleculares asociados a patógenos (PAMP) como el LPS (lipopolisacárido), produciendo de esta manera la secreción de citocinas como IL-6, TNF- $\alpha$, IL-1 $\beta$, IL-12 e IL-23 (Figura 5) y causando a su vez, condiciones de hipoxia en el tejido adiposo inflamado y, finalmente necrosis celular, seguido de una disfunción vascular y endotelial, que conduce a estrés oxidativo, que es una alteración en el equilibrio de la producción de especies reactivas de oxígeno (ROS), y de las defensas antioxidantes provocando la oxidación de las macromoléculas, lo que a su vez se asocia con complicaciones de la obesidad como lo son la resistencia a la insulina y la diabetes. ${ }^{23,3,24}$ A continuación en la Figura 5 se observa el mecanismo de las citocinas implicadas en el proceso inflamatorio sobre el tejido adiposo en personas con exceso de grasa y su comparación con el tejido adiposo de sujetos sanos.

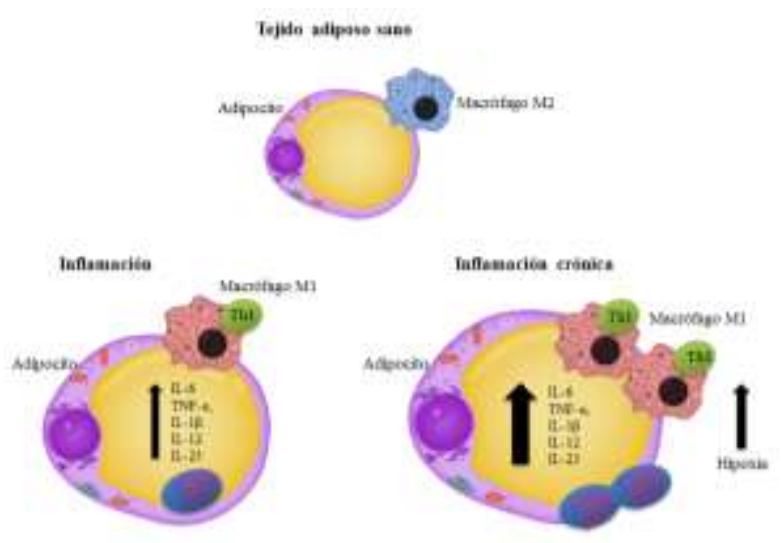

Figura 5. Proceso inflamatorio del tejido adiposo en la obesidad. Adaptado de 22

\section{Función biológica de la Vitamina E}

La función biológica es una serie de acciones efectuadas por los nutrientes que permiten el mantenimiento del organismo humano, para el caso particular de la vitamina $\mathrm{E}$, como se mencionó anteriormente, su principal función biológica es actuar como antioxidante y proteger a los lípidos (con dobles enlaces de su oxidación) que conforman a las membranas celulares, ${ }^{25}$ se ha indicado que el a-tocoferol es el compuesto químico con mayor actividad antioxidante, esto se debe a la capacidad redox que tiene su anillo cromanol que le permite ceder un hidrógeno para convertir a la vitamina $E$ en un radical que puede continuar su oxidación en a-tocoferil quinona (Figura 6) o reducirse por la vitamina C u otros componentes reductores para poder regenerarse, ${ }^{26}$ por lo que de esta forma capta el oxígeno e inhibe la producción de nuevos radicales libres, evitando la peroxidación lipídica. ${ }^{10}$<smiles>Cc1c(C)c2c(c(C)c1O)CC[C@@](C)(CCC[C@H](C)CCC[C@H](C)CCCC(C)C)O2</smiles><smiles></smiles> 
Figura 6. Reacción redox de la vitamina $E$ (color rojo indica la conversión de la Vitamina $E$ en un radical, para que continúe su oxidación debido a la capacidad redox de su anillo cromanol). (Perkin Elmer Informatics, Inc. 1998 $-2017)$.

No obstante, desempeña otras funciones biológicas beneficiosas para la salud humana, dentro de las cuales destaca su efecto antiinflamatorio suprimiendo una variedad de mediadores inflamatorios en todas sus isoformas, donde el $\mathrm{y}$-tocoferol, el $\delta$-tocoferol y los tocotrienoles pueden inhibir la inflamación en el colon y ofrecer un mecanismo anticarcinogénico. Asimismo, se ha observado que los tocotrienoles bloquean las vías de señalización del factor nuclear-kappa B (NF-kB) y Janus kinasesignals transducción y activación de la transcripción (JAK-STAT3) que median la expresión de diversas citocinas proinflamatorias (IL-1, IL-6 y TNF- $\alpha$ ), siendo el $\gamma$-tocotrienol el que presenta un mayor efecto. ${ }^{5}$

\section{Metodología}

El presente trabajo fue un diseño de revisión descriptiva, donde se realizó la búsqueda de artículos relacionados con la descripción de los efectos fisiológicos y biológicos de la vitamina $\mathrm{E}$ sobre los biomarcadores inflamatorios asociados a la obesidad. La fase de búsqueda se centró en artículos recuperables en la plataforma PubMed y ScienceDirect, mediante el uso de palabras clave como "Inflamación", "Tocoferol” y "Vitamina E”. Se consideraron los siguientes criterios para la selección de artículos: estudios indexados publicados en el periodo de 2015 hasta la actualidad, artículos publicados en inglés y/o español y estudios realizados en humanos y animales que presentaban datos originales sobre el efecto de la concentración de vitamina $E$ y sus isoformas sobre biomarcadores inflamatorios asociados a la obesidad. Una de las limitaciones más importantes se relacionó con la poca disponibilidad de estudios en humanos.

\section{Resultados}

Se encontraron 16 artículos (5 en animales, 2 in vitro (células humanas) y 9 en humanos), sin embargo, tras un extenso análisis se descartaron 8 de ellos, por no tener suficiente relevancia, resultando un total de 8 artículos con estudios realizados tanto en hombres como en mujeres con un rango de edad entre 20 a 85 años aproximadamente (Tabla 2 ).

Todos los estudios presentes en esta revisión evaluaron el efecto de la suplementación con vitamina $E$ en padecimientos relacionados con la obesidad que involucran procesos inflamatorios, utilizando la suplementación con vitamina $E$ en 2 estudios, $\alpha$-tocoferol en 3 estudios y $\delta$-tocotrienol en 3 estudios.

Tabla 2.- Efectos de la vitamina E sobre biomarcadores relacionados con el desarrollo de la obesidad

\begin{tabular}{|c|c|c|c|c|}
\hline Nutriente & Estudio & Concentración & Función biológica & Referencias \\
\hline \multirow{2}{*}{ Vitamina E } & $\begin{array}{c}41 \text { pacientes } \\
\text { con estenosis aórtica } \\
\text { degenerativa crónica } \\
\text { ( } 28 \text { hombres y } 13 \\
\text { mujeres de } 56 \text { a } 76 \\
\text { años de edad). }\end{array}$ & $400 \mathrm{UI} /$ día de vitamina $\mathrm{E}$ & $\begin{array}{c}\text { Reduce significativamente en suero la } \\
\text { Proteína C Reactiva (PCR) }(4.9 \mathrm{mg} / \mathrm{L} \text { inicial, } \\
4.1 \mathrm{mg} / \mathrm{L} \text { final }) .\end{array}$ & 27 \\
\hline & $\begin{array}{l}30 \text { pacientes con } \\
\text { Nefropatía Diabética } \\
\text { (11 hombres y } 19 \\
\text { mujeres de } 40 \text { a } 85 \\
\text { años de edad). }\end{array}$ & 1500 UI/día de vitamina E & $\begin{array}{c}\text { Reduce significativamente la PCR }(0.9 \mathrm{mg} / \mathrm{L} \\
\text { inicial, } 0.7 \mathrm{mg} / \mathrm{L} \text { final }), \mathrm{TNF}-\alpha(181.1 \mathrm{ng} / \mathrm{L} \\
\text { inicial, } 145.8 \mathrm{ng} / \mathrm{L} \text { final })\end{array}$ & 28 \\
\hline Tocoferoles & $\begin{array}{c}60 \text { pacientes con } \\
\text { antecedente de } \\
\text { hígado graso no } \\
\text { alcohólico ( } 48 \\
\text { hombres y } 12 \text { mujeres } \\
\text { de } 25 \text { a } 64 \text { años de } \\
\text { edad). }\end{array}$ & 400 UI/día RRR- $\alpha$-tocoferol & $\begin{array}{l}\text { Disminuye la Presión Arterial Sistólica (PAS), } \\
\text { TNF- } \alpha \text { (43.72 pg/mL antes, } 32.28 \mathrm{pg} / \mathrm{mL} \\
\text { después) y enzimas hepáticas. }\end{array}$ & 29 \\
\hline
\end{tabular}


Hidalgo, Vol. 10, No. 19 (2021) 1-8

\begin{tabular}{|c|c|c|c|c|}
\hline & $\begin{array}{l}44 \text { pacientes con } \\
\text { enfermedad de las } \\
\text { arterias coronarias } \\
\text { ( } 33 \text { hombres y } 11 \\
\text { mujeres de } 52 \text { a } 66 \\
\text { años de edad). }\end{array}$ & $\begin{array}{l}1200 \text { UI /día de } R R R-\alpha- \\
\text { tocoferol }\end{array}$ & $\begin{array}{c}\text { Reduce significativamente las concentraciones } \\
\text { de PCR a un } 32 \% \text { con la suplementación con } \\
\alpha \text { - tocoferol que con el placebo y TNF- } \alpha(16.2 \\
\text { ng/mg de proteína inicial, } 6.8 \mathrm{ng} / \mathrm{mg} \text { de } \\
\text { proteína final) }\end{array}$ & 30 \\
\hline & $\begin{array}{l}40 \text { pacientes con } \\
\text { diabetes mellitus } 2 \\
\text { (hombres de } 44 \text { a } 60 \\
\text { años de edad). }\end{array}$ & $400 \mathrm{UI} /$ día de $\alpha$-tocoferol & $\begin{array}{c}\text { Disminuye significativamente el nivel } \\
\text { plasmático de PCR }(3 \mathrm{mg} / \mathrm{dl} \text { antes de tx, } 2 \\
\mathrm{mg} / \mathrm{dl} \text { después del tx }) \text { y TNF- } \alpha(155 \mathrm{ng} / \mathrm{mL} \\
\text { inicial, } 41 \mathrm{ng} / \mathrm{mL} \text { final })\end{array}$ & 31 \\
\hline \multirow{3}{*}{ Tocotrienoles } & $\begin{array}{c}35 \text { pacientes con } \\
\text { esteatosis hepática } \\
\text { (Hombres y mujeres } \\
\text { de } 20 \text { a } 70 \text { años de } \\
\text { edad) }\end{array}$ & $\begin{array}{c}300 \mathrm{mg} / \mathrm{día}(447.00 \mathrm{UI} / \mathrm{dí}) \mathrm{de} \\
\text { tocotrienol }(90 \% \delta \text {-tocotrienol y } \\
10 \% \gamma \text { - tocotrienol })\end{array}$ & $\begin{array}{c}\text { Reduce de manera significativa los } \\
\text { marcadores inflamatorios (PCR } 0.91 \mathrm{mg} / \mathrm{L} \\
\text { inicial, } 0.61 \mathrm{mg} / \mathrm{L} \text { final, IL-6 } 3.42 \mathrm{pg} / \mathrm{mL} \\
\text { inicial, } 2.85 \mathrm{pg} / \mathrm{mL} \text { final y TNF- } \alpha 3.26 \mathrm{pg} / \mathrm{mL} \\
\text { inicial, } 3 \mathrm{pg} / \mathrm{mL} \text { final) }\end{array}$ & 32 \\
\hline & $\begin{array}{l}31 \text { adultos con } \\
\text { hipercolesterolemia } \\
(26 \text { hombres y } 5 \\
\text { mujeres }>50 \text { años de } \\
\text { edad }) \text {. }\end{array}$ & $\begin{array}{c}250 \mathrm{mg} / \text { día }(372.50 \mathrm{UI} / \text { día }) \mathrm{de} \\
\text { 8-tocotrienol }\end{array}$ & $\begin{array}{l}\text { Disminuye las concentraciones séricas de } \\
\text { PCR ( } 4.39 \mathrm{mg} / \mathrm{L} \text { inicial, } 2.63 \mathrm{mg} / \mathrm{L} \text { final })\end{array}$ & 33 \\
\hline & $\begin{array}{l}31 \text { adultos con } \\
\text { hipercolesterolemia } \\
\text { ( } 26 \text { hombres y } 5 \\
\text { mujeres de } 50 \text { a } 71 \\
\text { años de edad). }\end{array}$ & $\begin{array}{c}250 \mathrm{mg} \text { /día (372.50 UI/día) de } \\
\text { ס-tocotrienol }\end{array}$ & $\begin{array}{l}\text { Disminuye significativamente el TNF- } \alpha \\
\text { (100\% inical, } 48.5 \% \text { final) e IL-6 (100\% } \\
\text { inicial, } 38.5 \% \text { final) }\end{array}$ & 34 \\
\hline
\end{tabular}

\section{Discusión}

En la literatura hay poca disponibilidad de estudios de intervención con el uso de la vitamina $\mathrm{E}$, sin embargo, los hallazgos de este estudio demostraron que la suplementación con diversas dosis de vitamina E, tiene efectos positivos en la disminución de marcadores inflamatorios.

Esto se puede observar en un estudio por Fouladvand et al. (2020), ${ }^{27}$ quienes evaluaron la co-suplementación de vitamina $C$ y vitamina $E$ con la finalidad de comprobar su efecto sobre niveles séricos de PCR en pacientes con estenosis aórtica. El estudio demostró que la suplementación con 400 Ul/día de vitamina E y C tuvo un efecto antiinflamatorio en la Estenosis Aórtica degenerativa crónica, al reducir la PCR de $4.9 \mathrm{mg} / \mathrm{L}$ a 4.1 $\mathrm{mg} / \mathrm{L}$ después de la suplementación con vitamina E. Esto se apoya en un estudio que buscó examinar la asociación entre la ingesta de 5 nutrientes antioxidantes (vitamina $E$ y C, carotenoides, Se y Zn) y niveles de PCR de alta sensibilidad, concluyendo que la suplementación de vitamina $E$ combinada especialmente con vitamina $\mathrm{C}$, se asoció mayormente con niveles menores de PCR. ${ }^{35}$

Por otra parte, Ekhlasi et al. (2017), ${ }^{29}$ evaluó los efectos de la suplementación simbiótica y de vitamina E sobre los índices inflamatorios de pacientes con hígado graso no alcohólico. El estudio mostró que la suplementación con
400 Ul/día de a-tocoferol resultó en una disminución del TNF- $\alpha$ de $43.72 \mathrm{pg} / \mathrm{mL}$ a $32.28 \mathrm{pg} / \mathrm{mL}$ después del tratamiento.

Khatami et al. (2016). ${ }^{28}$ También investigó el efecto de la vitamina $\mathrm{E}$ sobre biomarcadores de daño renal, inflamación y estrés oxidativo en pacientes con Nefropatía Diabética. Su estudio evidenció que la suplementación oral de vitamina $\mathrm{E}$ a dosis altas (1500 Ul/día) tuvo efectos favorables sobre dichos biomarcadores, puesto que redujo de manera significativa la PCR de $0.9 \mathrm{mg} / \mathrm{L}$ a $0.7 \mathrm{mg} / \mathrm{L}$ y TNF- $\alpha$ de $181.1 \mathrm{ng} / \mathrm{L}$ a $145.8 \mathrm{ng} / \mathrm{L}$ después de la suplementación.

Así mismo, Asbaghi et al. (2020), ${ }^{30}$ investigaron el efecto de la suplementación con vitamina $E$ sobre los biomarcadores inflamatorios en adultos. Se observó que la suplementación con 1200 Ul/día de a-tocoferol disminuyó significativamente las concentraciones de PCR en un $32 \%$ después del tratamiento y de TNF- $\alpha$ de $16.2 \mathrm{ng} / \mathrm{mg}$ a $6.8 \mathrm{ng} / \mathrm{mg}$. No obstante, Jamalan et al. (2015), ${ }^{31}$ quien evaluó el efecto de la suplementación con $\alpha$-tocoferol sobre los niveles séricos de PCR y TNF- $\alpha$, evidenció que incluso la suplementación con dosis más bajas (400 Ul/día) de a-tocoferol también reduce de manera significativa los niveles plasmáticos de PCR (de $3 \mathrm{mg} / \mathrm{dL}$ a $2 \mathrm{mg} / \mathrm{dL}$ ) y TNF- $\alpha$ de $(155 \mathrm{ng} / \mathrm{mL}$ a $41 \mathrm{ng} / \mathrm{mL}$ ) después del tratamiento. Lo que podría indicar que la suplementación con vitamina $E$ tanto en dosis altas como bajas podría mostrar efectos positivos en la disminución de biomarcadores inflamatorios. 
Por su parte, en otra publicación realizada por Pervez et al. (2018), ${ }^{32}$ se estudiaron los efectos de la suplementación con $\delta$-tocotrienol sobre los marcadores bioquímicos de lesión hepatocelular y esteatosis en pacientes con enfermedad del hígado graso no alcohólico (EHGNA), encontrando una disminución significativa en niveles de PCR $(0.91 \mathrm{mg} / \mathrm{L}$ a $0.61 \mathrm{mg} / \mathrm{L}), \mathrm{IL}-6(3.42 \mathrm{pg} / \mathrm{mL}$ a $2.85 \mathrm{pg} / \mathrm{mL})$ y TNF- $\alpha(3.26 \mathrm{pg} / \mathrm{mL}$ a $3 \mathrm{pg} / \mathrm{mL})$, posterior a la suplementación con $300 \mathrm{mg} /$ día de tocotrienol $(90 \%$ $\delta$-tocotrienol y $10 \% \mathrm{y}$ - tocotrienol).

Además de eso, Quereshi et al. (2015), ${ }^{33}$ estudió el efecto del $\delta$-tocotrienol a dosis crecientes de $(125,250,500$ y 650 $\mathrm{mg} / \mathrm{d}$ ía) sobre los biomarcadores de estrés oxidativo e inflamatorio y demostró que todas las concentraciones de $\delta$-tocotrienol redujeron los niveles séricos de PCR, siendo la dosis de $250 \mathrm{mg} /$ día la más efectiva con una reducción de $4.39 \mathrm{mg} / \mathrm{L}$ a $2.63 \mathrm{mg} / \mathrm{L}$ después de la suplementación. Dicha concentración fue empleada en otro estudio por Quereshi et al. (2015) ${ }^{34}$ que evaluaba el efecto del $\delta$ tocotrienol sobre los niveles de TNF- $\alpha$ e IL-6 y se observó una disminución del 51.5 y $61.5 \%$ respectivamente, al final del tratamiento.

El impacto que generan las complicaciones asociadas a la obesidad en la calidad de vida y con ello en la salud, ha hecho necesario establecer una serie de tratamientos que van desde los cambios en el estilo de vida, actividad física y dieta. Es por ello que, en este último punto, se recomienda una ingesta diaria de vitamina E de $15 \mathrm{mg} / \mathrm{día}$ (equivalente a $22.35 \mathrm{UI} / d i ́ a)$, para obtener los beneficios, debido a su relación con los procesos inflamatorios. ${ }^{36}$

Además, si la población no consume alimentos con este nutriente, se sugiere que sea ingerido de suplementos, ya que estos presentan concentraciones de hasta $1500 \mathrm{IU}$ (ingesta diaria tolerable/día) equivalente a $1000 \mathrm{mg} / \mathrm{día}$, que aporta los requerimientos necesarios para que la vitamina $\mathrm{E}$ cumpla con sus funciones biológicas. ${ }^{37}$

\section{Conclusión}

La vitamina $E$ ejerce un efecto inhibidor en los niveles de biomarcadores inflamatorios relacionados con la obesidad. Por lo tanto, podemos señalar que la ingesta de vitamina $\mathrm{E}$ a una concentración de $400 \mathrm{UI} / \mathrm{día}$, tiende a ser más efectiva, de modo que, podría sumarse al tratamiento de la misma, sin embargo, antes de poder hacer tal aseveración hace falta mayor cantidad de estudios de intervención que permitan determinar claramente el papel de la vitamina $E$ en la obesidad.

\section{Referencias}

1. Zhao L, Fang X, Marshall M, Chung S. Regulation of obesity and metabolic complications by gamma and delta Tocotrienols. Molecules 2016; 21(3): 344.

2. Shamah-Levy T, Vielma-Orozco E, Heredia-Hernández O, Romero-Martínez M, Mojica-Cuevas J, Cuevas-Nasu L, Santaella-Castell JA, Rivera-Dommarco J. Encuesta Nacional de Salud y Nutrición 2018-19: Resultados Nacionales. Cuernavaca, México: Instituto Nacional de Salud Pública, 2020.

3. Ellulu MS, Patimah I, Khaza'ai H, Rahmat A, Abed Y. Obesity and inflammation: the link mechanism and complications. Archivos de ciencia médica 2017, 13(4): 851-863.

4. Lovati AB, Bottagisio M, Maraldi S, Violatto MB, Bortolin M, De Vecchi E, Bigini P, Drago L, Romanò CL. Vitamin E Phosphate Coating Stimulates Bone Deposition in Implantrelated Infections in a Rat Model. Clin. Orthop. Relat. Res. 2018; 476 (6):1324-1338.

5. Abraham A, Kattor A, Saldeen T, Mehta J. Vitamin E and its anticancer effects. Crit Rev Food Sci Nutr 2018; 59 (17): 28312838 .

6. Magariño M, Mateo CM, Nolasco SM. Kinetics of tocopherol degradation during the storage of wheat germ oil. Can. J. Chem 2015; 93 (11): 1999-2004.

7. Gedi MA, Briars R, Yuseli F, Zainol N, Darwish R, Salter AM, Gray DA. Component analysis of nutritionally rich chloroplasts: recovery from conventional and unconventional Green plant species. J. Food Sci. Technol. 2017; 54(9): 2746-2757.

8. Meydani S, Lewis E, Wu D. Should vitamin E recommendations for older adults be increased?. Adv Nutr 2018; 9 (5): 533-543.

9. Reboul E. Vitamin E Bioavailability: Mechanisms of Intestinal Absorption in the Spotlight. Antioxidants 2017; 6(4): 95. (5)

10. Mazur E, Litch N. Lutz's nutrition and diet therapy. En: Vitamins. 7th ed. Philadelphia: F.A. Davis Company; 2018: 7879.

11. Yuan P, Cui S, Liu Y, Li J, Du G, Liu L. (2020). Metabolic engineering for the production of fat-soluble vitamins: advances and perspectives. Appl. Microbiol. Biotechnol. 2020; 104 (3): 935-951.

12. Gay MA. Nutrición. En: Alimentos y su composición. España: Ministerio de educación y formación profesional; 2018: 14.

13. Pasias I, Kiriakou I, Papakonstantinou L, Proestos C. Determination of Vitamin $\mathrm{E}$ in cereal products and biscuits by GC-FID. Foods 2018; 7 (3): 1-6.

14. Sában J. Control global del riesgo cardiometabólico II: La disfunción endotelial como diana preferencial. En: Análisis crítico de la suplementación con antioxidantes. Madrid, España: Ediciones Díaz de Santos; 2017:781-782.

15. Gesteiro E, Galera J, González M. Aceite de palma y salud cardiovascular: consideraciones para valorar la literatura. Nutr Hosp 2018; 35(5): 1229-1242. 
16. Shahidi F, Costa de Camargo, A. Tocopherols and tocotrienols in common and emerging dietary sources: Occurrence, Applications, and Health Benefits. Int. J. Mol. Sci. 2016; 17(10): 1745 .

17. Granda L, Rosero A, Benešová K, Pluháčková H, Neuwirthová, J, Cerkal, R. Content of Selected Vitamins and Antioxidants in Colored and nonpigmented varieties of quinoa, Barley, and Wheat Grains. J. Food Sci. 2018; 83 (10): 2439-2447.

18. Schmölz L, Birringer M, Lorkowski S, Wallert M. Complexity of vitamin E metabolism. World J. Biol Chem. 2016, 7(1): 14 43.

19. Jiang Q. Natural forms of Vitamin $\mathrm{E}$ as effective agents for cancer prevention and therapy. Adv Nutr 2017, 8(6): 850-867.

20. McBurney MI, Yu EA, Ciappio ED, Bird JK, Eggersdorfer M, Mehta S. Suboptimal Serum $\alpha$-Tocopherol concentrations observed among younger adults and those depending exclusively upon food sources, NHANES 2003-2006. PLOS ONE 2015, 10(8): e0135510.

21. Schett G, Neurath MF. Resolution of chronic inflammatory disease: universal and tissue-specific concepts. Nat. Commun 2018, 9: 3261 .

22. Krüger K. Inflammation during Obesity-Pathophysiological concepts and effects of physical activity. Dtsch. Z. Sportmed. 2017, 68:163-169.

23. Castoldi A, Naffah de Souza C, Câmara NOS, Moraes-Vieira PM. The macrophage switch in obesity development. Front Immunol. 2016, 6: 1-11.

24. Masschelin PM, Cox AR, Chernis N, Hartig SM. The impact of oxidative stress on adipose tissue energy balance. Front. Physiol. 2020, 10: 1-8.

25. Calvo BS, Gómez CC, López NC, López BP. Manual de Alimentación. Planificación alimentaria. En: Santamaria JB Valero PM, Alarcón QN, Palma MS, López PB, Gómez CC, editors. Los nutrientes: vitaminas minerales y oligoelementos. Madrid. Editorial UNED; 2016.

26. Niki E. Evidence for beneficial effects of vitamin E. Korean J Intern Med. 2015; 30(5): 571-579.

27. Fouladvand F, Falahi E, Asbaghi O, Abbasnezhad A. Effect of vitamins $\mathrm{C}$ and $\mathrm{E}$ Co-Supplementation on serum $\mathrm{C}$ - reactive protein Level: A systematic review and meta-Analysis of randomized controlled trials. Prev. Nutr. Food Sci. 2020, 25 (1):1-8.

28. Khatami PG, Soleimani A, Sharifi N, Aghadavod E, Asemi Z. The effects of high-dose vitamin $\mathrm{E}$ supplementation on biomarkers of kidney injury, inflammation and oxidative stress in patients with diabetic nephropathy: a randomized, doubleblind, placebo-controlled trial. J Clin Lipidol. 2016, 10(4): 922 929.

29. Ekhlasi G, Zarrati M, Agah S, Hosseini AF, Hosseini S, Shidfar S, Soltani Aarbshahi SS, Razmpoosh E, Shidfar F. Effects of symbiotic and vitamin E supplementation on blood pressure, nitric oxide and inflammatory factors in non-alcoholic fatty liver disease. EXCLI J. 2017, 16: 278-290.

30. Asbaghi O, Sadeghian M, Nazarian B, Sarreshtedari M, Mozaffari-Khosravi H, Maleki V, Alizadeh M, Shokri A,
Sadeghi O. The effect of vitamin E supplementation on selected inflammatory biomarkers in adults: a systematic review and meta-analysis of randomized clinical trials. Sci. Rep 2020, 10 (1):17234.

31. Jamalan M, Rezazadeh M, Zeinali M, Ghaffari MA. Effect of ascorbic acid and alpha-tocopherol supplementations on serum leptin, tumor necrosis factor alpha, and serum amyloid A levels in individuals with type 2 diabetes mellitus. Avicenna J Phytomed. 2015, 5(6): 531-539.

32. Pervez MA, Khan DA, Slehria AUR, Ijaz A. Delta-tocotrienol supplementation improves biochemical markers of hepatocellular injury and steatosis in patients with nonalcoholic fatty liver disease: A randomized, placebo-controlled trial. Complement Ther Med. 2020, 52: 1-7.

33. Qureshi AA, Khan DA, Mahjabeen W, Trias AM, Silswal N, Qureshi N. Impact of $\delta$-Tocotrienol on inflammatory biomarkers and oxidative stress in hypercholesterolemic subjects. J. Clin. Exp. Cardiol. 2015, 6 (4): 2-9.

34. Qureshi AA, Khan DA, Mahjabeen W, Qureshi N. Dosedependent Modulation of Lipid Parameters, Cytokines and RNA by $\delta$-tocotrienol in hypercholesterolemic subjects restricted to AHA Step-1 Diet. JAMMR. 2015, 6(4): 351-66.

35. Schwab S, Zierer A, Schneider A, Heier M, Koenig W, Kastenmüller G, Waldenberger M, Peters A, Thorand B. Vitamin E supplementation is associated with lower levels of Creactive protein only in higher dosages and combined with other antioxidants: The Cooperative Health Research in the Region of Augsburg (KORA) F4 study. Br. J. Nutr. 2015, 113(11): 178291.

36. Valisek J, Koplik R, Cejpek K. The Chemistry of Food. En: Vitamins. 2nd ed. United Kingdom: John Wiley \& Sons Ltd, 2020: 386 .

37. Combs Jr GF, McClung JP. The Vitamins. En: Vitamins needs and safety. 5th ed. United States: ELSEVIER, 2017: 104 